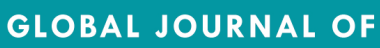 \\ Community Psychology Practice
}

\section{PROMOTING COMMUNITY PRACTICE FOR SOCIAL BENEFIT}

The Role of Ethnic Identity in Interventions to Promote Positive Adolescent

\section{Development}

\author{
Jean L. Hill \\ New Mexico Highlands University \\ GiShawn A. Mance \\ American University \\ Riana Elyse Anderson \\ University of Virginia \\ Emilie P. Smith \\ The Pennsylvania State University
}

Author Note: This article is based upon a symposium presented at the $13^{\text {th }}$ Biennial Conference of the Society for Community Research and Action, June 16-19, 2011, Chicago Illinois.

Keywords: adolescent development, ethnic identity

Recommended citation: Hill, J. L., Mance, G. A., Anderson, R. E., \& Smith, E. P. (2012). The role of ethnic identity in interventions to promote positive adolescent development. Global Journal of Community Psychology Practice, 2(3), 1-12. Retrieved Day/Month/Year, from (http://www.gjcpp.org/). 


\title{
The Role of Ethnic Identity in Interventions to Promote Positive Adolescent Development
}

\author{
Jean L. Hill, GiShawn A. Mance, Riana Elyse Anderson, Emilie P. Smith
}

\begin{abstract}
This paper addresses the role of ethnic identity in child development. We report on two school-based interventions with a focus on strengthening the ethnic identity of girls, one with a Hispanic population and one with an African American population. We also report on a study investigating whether parental ethnic identity plays a mediating role in African American parenting styles. The results of each study were non-significant in relation to their specific hypotheses regarding ethnic identity. We discuss the implications of these non-significant findings, particularly given that the two interventions were conducted in minority-majority communities.
\end{abstract}

\section{Introduction}

Interviewer: "What makes being Hispanic different from being African-American or Anglo or any of those other groups to you?"

Participant: 'I'm not sure but I think it's because everybody, mostly everybody I know, they're Hispanic. Like all my family and all my friends and everything."

Interviewer: "What makes being Hispanic different from being another race and culture?"

Participant: "I think you fit in more."

Interviewer: "Fit in more? In this school or..."

Participant: "Everywhere."

Interviewer: "Everywhere, okay."

Participant: "Except for Texas."

The quote is from a $5^{\text {th }}$ grade girl in a school district in rural county in northern New Mexico where 77\% of the population identifies as Hispanic (US Census Bureau, 2010). Her response reflects the fact that she was born and raised in a minority-majority community; a community in which her ethnic identity is a visible, celebrated part of community life. For adolescents of color, the successful transition to healthy functioning in adulthood requires the achievement of a secure sense of their ethnic or racial identity in light of stereotypical images of their group, cultural differences and conflicts, and restricted opportunities (Phinney \& Kohatsu, 1997). The role of one's ethnic group status is deemed to be pivotal within understanding and defining the adolescent's process of ethnic identity. In this paper we will present three studies that focused partially and in various ways on the role of ethnic identity in child and adolescent functioning. All of them were conducted with populations who lived in minoritymajority communities; a circumstance that we believe had a significant impact on our findings.

The past several decades have seen the generation of a great deal of research on the development of ethnic identity and its role in positive functioning. Models of ethnic identity development tend to mirror Marcia's stages of identity development, particularly his concepts of identity diffusion and identity achievement (Marcia, 1996). Models of ethnic identity development include the concepts of immersion (a period of intensive involvement with one's own racial/ethnic group) and ultimately transformed relations with the mainstream culture. As with all models incorporating stage concepts, they have the limitation (recognized by their developers) that not everyone goes through each stage or in the specified order.

Research on the role of ethnic identity has yielded varying results. It seems clear that experiences with discrimination and negative stereotypes are damaging for members of minority cultures (Sellers \& Shelton, 2003; Williams \& Williams-Morris, 2000). A strong, positive ethnic identity has been found to correlate with various aspects of adaptive functioning, including self-esteem, drug use, commitment to education, less aggression, more pro-social behaviors (Caldwell, Kohn-Wood, Schmeelk-Cone, Chavous, \& Zimmerman, 2004; McMahon \& Watts, 2002). Relatedly, many studies have found that a strong, positive ethnic identity and sense of belonging is beneficial, and may serve as a protective factor when discrimination and prejudice are encountered (Sellers, Caldwell, Schmeelk-Cone, \& Zimmerman 2003; Caldwell et al., 2004). 
In addition, several studies have generated findings suggesting that a negative attitude toward the majority culture is associated with negative effects, such as lowered commitment to educational goals and less pro-social behavior. Oppositional identity refers to an ethnic identity that is distrustful of and includes negative perceptions of the dominant culture (Fordham \& Ogbu, 1986). Some research has found a correlation between an oppositional identity and negative attitudes toward school, fewer prosocial behaviors, alcohol and marijuana use (Resnicow, Baranowski, Ahluwahlia, \& Braithwaite, 1999; Irving \& Hudley, 2008).

These findings are in no way universal, with some research finding them true for some minority ethnic groups but not others, or one gender but not the other. Overall, the basic conclusion of this research is that a positive view of one's own racial/ethnic group, including a sense of inclusion and belonging, coupled with a positive view of the majority culture, supports adaptive functioning and has protective effects. These findings have lead to research on how to strengthen ethnic identity in young minority group members. Two potential avenues for doing this are through planned interventions and through parental ethnicracial socialization practices. Research has demonstrated that both of these avenues can be effective ways of supporting positive ethnic identity development (Belgrave, Chase-Vaughn, Gray, Addison, \& Cherry, 2000; Hughes et al., 2006).

\section{Study One, "Cuentos From My Childhood": The Use of Culturally Relevant Folktales to Support the Healthy Development of Hispanic Girls}

The term Hispanic is used to describe a broad array of cultures in the United States, each with different histories, cultural traditions, and immigration patterns. The Hispanic population in northern New Mexico consider themselves to be an indigenous Hispanic community, in that the community existed in this region before the area became part of the United States. The first Spanish settlers came to the area in the $17^{\text {th }}$ century and many families still describe their ethnicity as Spanish. The most commonly used ethnic descriptor is Hispanic, with Latino/a and Chicano/a used only rarely. The term Mexican or Mexican American is used specifically in cases where the individual or one of his or her immediate ancestors immigrated to the United States from Mexico.
Hispanic culture, identity, and the Spanish language (particularly the regional variation) are all of central importance to the communities in the area. Concerns about losing that identity are frequently expressed and many community initiatives focus on supporting and celebrating that Hispanic cultural identity.

This study reports on an intervention that was designed to support the development of healthy selfesteem and interpersonal relationships among $5^{\text {th }}$ grade girls through participation in an activity group based upon the reading and interpretation of folktales, particularly a collection of Hispanic folktales. The analysis presented in this paper will focus on interview responses from the girls regarding their conception of their ethnic identity.

\section{Method}

The project was conducted over a two-year period. For the purposes of this analysis we will be comparing girls who participated in a story group (the intervention curriculum) with girls who participated in an arts and crafts group (the control group). Altogether 38 girls participated in the story group (of whom 33 completed interviews) and 32 girls participated in the arts and crafts group (of whom 27 completed interviews). Twenty-eight (85\%) of the girls in the story group self-identified as Hispanic (85\%), along with $22(82 \%)$ of the girls in the arts and crafts group. All the girls were in the $5^{\text {th }}$ grade. The intervention was held once a week for thirteen weeks during the regular school day.

The story group curriculum was based upon feminist theories regarding the central role of relationships to self-esteem among women and girls, and theories regarding the use of narratives (stories), particularly cultural narratives, as a means of supporting personal growth. Each girl received a copy of the book "Cuentos From My Childhood: Legends and Folktales of Northern New Mexico" by Paulette Atencio (1991), as well as copy of fairy tales by the Brothers Grimm. "Cuentos From My Childhood" is a bilingual book, with each story presented in both English and Spanish.

All the girls completed a self-report measure of selfesteem (the Multidimensional Self Concept Scale; Bracken, 1992) before and after participating in the groups.

\section{Results and Discussion}

Data from the Multidimensional Self Concept Scale indicated that the intervention had no measurable 


\section{Global Journal of Community Psychology Practice}

effect on self-esteem (for additional details regarding this analysis please contact the first author). Data from interviews suggest that the groups did have a positive effect on interpersonal relationships among the girls, particularly a decrease in bullying, a finding which was supported by the observations of the teachers. However, this result was found for the girls participating in the arts and crafts group as well as in the story group. In addition, there was little support in the interviews for any change in the girls' perceptions of their ethnic identity, even though this was an explicit focus of the story group curriculum.

The analysis conducted for this paper was an attempt to further understand the girls' perceptions of their ethnic identity. The analysis will focus specifically on the following four questions from the interview:

1. How would you describe yourself?

2. Different people consider themselves members of different groups. For instance people might consider themselves Hispanic, Latino, Mexican, Anglo, African American, or Native American. Do you consider yourself a member of any of those groups?

3. What does being mean to you?

4. What makes being ___ different from being a member of another group?

Throughout the two years of the project not a single girl spontaneously included her ethnicity in her response to the question "How would you describe yourself?" In the second year of the project we changed the order of the questions and asked the questions "How are you like your friends?" and "How are you like your family?" after the initial question about describing yourself. With this order two girls mentioned ethnicity when describing how they were like their families, but neither were Hispanic. Several of the girls were resistant to identifying themselves with a particular ethnic group, giving responses such as "I'm just a person" or "I don't think it really matters."

When asked what being Hispanic means to them, or what makes being Hispanic different from being a member of another group many of the girls responded "nothing" or "I don't know." But the majority response was that being Hispanic meant speaking both Spanish and English. A typical response was "Being Hispanic means speaking Spanish good. I was raised with a Spanish family but I don't really speak it that much. I just speak English more than Spanish." The girls clearly identified speaking two languages as a positive thing, and something not everyone can do. "That I know two different languages. Spanish and English. Not all people can speak Spanish.”

There were clear indications in the answers that the girls tended to think of being Hispanic/Spanish as being bilingual. They did not associate that ethnic identity with being monolingual Spanish speaking. There was a clear differential between the terms Spanish and Mexican, with Spanish implying bilingual. "Like some half Hispanic and half Mexican. Because I'm Spanish and Mexican. I like that I speak Spanish and I speak English."

While we did not ask the girls specifically about role models, two girls did spontaneously mention women they admired, one when she was talking about her idea of the ideal girl and the other when discussing her intended career. Both of the women mentioned were Hispanic, but neither girl mentioned that when discussing the women.

Not a single girl, from any ethnic group, mentioned a negative perception of her ethnic group or experiences of discrimination or prejudice. Several girls who identified as Hispanic, like the girl quoted at the beginning of this article, mentioned that being Hispanic meant you were like everyone else, that you were part of an in-group. "I just like the religions and the celebrations. It makes me feel like I'm in."

The girls from ethnic groups that are a minority in the region also expressed positive feelings about their ethnic group, but they tended to feel that it was cool to be different. "Because a lot of people aren't that kind of culture. And I think it kind of makes me kind of special because its from a different culture and a lot of people don't know about that culture so that's kind of cool."

As with the quantitative measure, there were no identifiable differences in the interview responses between the girls in the story group and those in the arts and crafts group. There were also no identifiable differences in their responses before and after participating in the groups. It seems quite clear from their responses that the girls in the story group had no idea that a goal of the group was to strengthen Hispanic ethnic identity.

When asked what they thought the goal of the group was the response was universal - to improve relationships among the girls. When asked if they thought that goal had been met they all believed it 
had. They believed that they got along better and that there was more respect, less fighting, more friendships, and less bullying among the girls. This belief was echoed by their teachers, who stated that they saw improved relationships among the girls who participated in both the story and the arts and crafts groups. This was true even though group leaders reported that the cultural aspect of the intervention was salient in the story group. The cultural relevance of some of the stories was specifically discussed and the girls shared versions of the folktales as they were told in their families.

The concepts of biculturality and bicultural competence seem to be reflected in the girls' responses. The majority of the girls in this study expressed a clear ethnic identity and had a positive interpretation of that identity. But the characteristic that most clearly defined their culture for them was being bilingual, an aspect of bicultural competence. For them, in a sense, being Hispanic means being bicultural.

Both of these findings, the existence of a strong positive ethnic identity among the majority of the girls and the conceptualization of Hispanic identity as bicultural, are probably the result of the unique nature of Northern New Mexico Hispanic culture. These girls grew up in communities where their culture has been the dominant culture for hundreds of years. Their culture has always been presented to them as something to be proud of, and it is unlikely, at this stage of their lives, that they have ever directly experienced discrimination because of their ethnicity.

Given this, it seems reasonable to assume that they girls did not take note of the cultural nature of the story group because a focus on Hispanic culture is a normal part of their lives, including their education. This would also be a reasonable explanation for why there was no evidence of the intervention having an effect on ethnic identity. In contrast, the girls in both groups were very aware of the gendered nature of the groups and believed that was related to their purpose.

\section{Study Two, Beautiful Butterflies: Considerations for Culturally-Relevant Community Interventions for African American Girls}

The second study presented in this paper was also an evaluation of a school-based intervention, Project Butterfly. Project Butterfly was an 8-week African centered intervention, designed to enhance African cultural values, ethnic identity, and psychological well-being among $6^{\text {th }}$ to $8^{\text {th }}$ grade African-American girls. The project was conducted in two elementary schools in Chicago, Illinois. Both schools were located in Chicago's inner city. At least $98 \%$ of the students in both schools were eligible for a federallyfunded lunch program and thus labeled low-income (Chicago Public Schools Annual Report, 2003). The schools were $100 \%$ African American with daily attendance rates at $92 \%$ and the truancy rates at $1 \%$ (Chicago Public Schools Annual Report, 2003). Thus, as with the intervention in New Mexico, the girls were from a minority-majority community.

Unlike the project in New Mexico, the evaluation of Project Butterfly included specific quantitative measures of racial/cultural values and ethnicity. Project Butterfly had a strong focus on directly teaching Africentric values to the participants. Research illustrates that Africentric values are related to psychological well being among African American youth (Belgrave et al, 2002). This finding is separate from the well-supported finding that racial/ethnic identity is related to psychological outcomes (Arbona, Jackson, McCoy, \& Blakely, 1999; Caldwell et al., 2002; McCreary, Slavin, \& Berry, 1996; Romero \& Roberts, 1998). For that reason a measure of cultural values and attitudes (the African Cultural Values Scale; Nobles \& Goddard, 1992) as well as a measure of racial/ethnic identity were used in the study.

Research on African American youth focuses on racial identity rather than ethnic identity (Caldwell et al., 2002). One's ethnic identity entails not only identification based on physical traits, but also basic feelings, beliefs, and attitudes about one's ethnic group that are consistent with one's cultural values. Understanding race is particularly important for African Americans given their historical experiences in the U.S. Therefore, a measure that was specifically developed for African American youth, which incorporates elements of both ethnic and racial identity, the Multi-Construct of African American Identity Questionnaire (MCAIQ; Smith \& Brookins, 1997), was used in this study. The MCAIQ was developed to examine ethnic identity, which the authors defined as racial orientation. Racial orientation refers to attitudes toward African Americans as a group (Smith \& Brookins, 1997). This measure was designed to identify components of a positive ethnic identity specifically for early adolescent African Americans.

\section{Method}




\section{Global Journal of Community Psychology Practice}

A sample of 93 African American 6th - 8th grade adolescent girls attending two elementary schools in Chicago, Illinois completed both pre- and post-test measures for the study. One school served as the intervention school, while the other served as the comparison school. Interested $6^{\text {th }}, 7^{\text {th }}$ and $8^{\text {th }}$ grade were invited to participate in the study and received a research packet, which consisted of a research introduction letter, student consent forms and parental consent forms. Girls in the intervention school also received an intervention flyer, describing Project Butterfly.

Of the sample, $51 \%(n=47)$ of the girls comprised the intervention group, while the remaining $49 \%$ ( $n=$ 46) constituted the comparison group. Participants ranged from 11 to 15 years of age with a mean of 12.5 years $(S D=.95)$. There were no demographic differences between the groups except for a significant difference according to grade, $t(93)=$ 12.37, $p<.001$. Participants from the control school tended to be in a higher grade $(M=7.1, S D=.83)$ compared to intervention participants $(M=6.5, S D=$ $.50)$.

The 8-week Project Butterfly intervention sessions were conducted during the weekly non-instructional period, which was a 45-minute "free/study" period where the students did not receive a structured activity (e.g., art, music, physical education, and computer). Six classrooms participated in the intervention; therefore, there were six groups that met weekly during their individual "free periods" for 45 minutes during the eight-week intervention period.

Demographic characteristics were collected from each participant, including race/ethnicity, age, grade, number of siblings, primary caregiver, and parental level of education. Psychological well-being was assessed using the Youth Self-Report (YSR) of the Achenbach Behavior Checklist (Achenbach, 1991). Cultural values and attitudes were assessed using the African Cultural Values Scale (ACVS; Nobles \& Goddard, 1992). The Multi-Construct of African American Identity Questionnaire (MCAIQ; Smith \& Brookins, 1997) was used to assess participants' racial/ethnic identity. The complete protocol was administered in a group format based on grade. The questionnaire administration took approximately 1 hour to complete at pre- and post-test.

Additionally, a focus group with ten Project Butterfly participants was conducted to gather more detailed information on female African American adolescent identity.

\section{Results and Discussion}

An ANCOVA was conducted to test the effects of Project Butterfly on the main study variables. Pre-test scores of each dependent variable were controlled for in analyses. Project Butterfly was found to have a significant main effect on African cultural values, $F(2,89)=10.97, p<.01)$. Intervention participants had stronger cultural values at post-test $(M=42.23$; $S D=4.05)$ than control participants $(M=40.45 ; S D$ $=4.52$ ). The second ANCOVA was conducted to determine if there was a difference between the intervention and control groups on ethnic identity after the intervention took place, while controlling for ethnic identity at pre-test. No significant difference was found on ethnic identity between girls participating in Project Butterfly and those who did not, $F(1,91)=.54$, ns.

A hierarchical regression showed that stronger African cultural values predicted a stronger ethnic identity at post-test, $F(2,90)=19.47, \beta=.30, p<.01$. Similarly, African cultural values at pre-test predicted stronger ethnic identity at post-test, $F(2,89)=19.12$, $\beta=.23, p<.01$.

Ethnic identity did not predict psychological wellbeing at post-test, while controlling for well-being at pre-test, $F(2,90)=25.00, \beta=-.02, n s$. An additional regression revealed that ethnic identity at pre-test did not predict psychological well-being at post-test, $F(2,89)=26.97, \beta=.14, n s$. (for additional details regarding this analysis please contact the second author).

To gain more clarity to the quantitative results, a subset of 10 Project Butterfly participants completed a focus group to further explore ethnic identity. Participants responded to two questions.

When asked, "What does it mean to be Black/African American?" the girls commented that it was hard, but also expressed pride in their culture, as in this answer, "Sometimes hard, sometimes alright because everyone wants to be like us." Another girl related the difficulties of being African American to conflict within the community, conflict that is supported by the majority culture.

"It's hard because they [majority culture] don't want us to be together. One nation. 'Cause I know, I noticed they are all together; they have their own schools, hospitals, buses, and 
everything. But you see Black people, they split up and always fighting. You don't see them talking bad to each other."

When asked, "How do you feel about being an African American girl?" the girls reported pride, and anger at the way the they are viewed by the majority culture. "Sometimes we are seen as statistics, but I don't let those statistics have control over me. It makes me mad...see bad and think we all bad."

Interestingly, girls participating in Project Butterfly did not report a stronger sense of ethnic identity after the intervention. In this study, racial/ethnic identity was measured by the extent one rejected negative stereotypes, appreciated the physical characteristics of African Americans, and interacted with one's ethnic group. It is possible that the participants in the study had a healthy sense of identity prior to the intervention and exposure to Project Butterfly did not significantly affect their overall sense of identity. Participants attended schools and lived in neighborhoods that were 100\% African American. It is highly probable that the participants received many positive cultural messages prior to the intervention. Thus, exposure to the curriculum may have reiterated cultural messages already relayed within the community rather than introduce concepts.

Therefore, exposure to Project Butterfly may not have impacted these components of ethnic identity. Additionally, the intervention focused on a number of concepts that may not have strongly impacted one's acceptance or rejection of stereotypical portrayals of African Americans, which may have also impacted the current findings related to ethnic identity.

Project Butterfly was designed to specifically address the cultural and gendered experiences of African American girls. However, the emphasis on genderrelated material may have been more salient than ethnicity for participants. Given that African American females are recipients of both gender and racial bias (DuBois, 2002), a program designed with a gender-specific component may have spoken more to the girls' gendered experiences rather than their ethnic experiences.

Study 3 Black Parenting Power: An Exploratory Analysis of the Impact of Ethnic Identification on Low-Income African American Parenting Style and Child Outcome

Parenting style has been widely evaluated with respect to child outcome (Jones et al., 2008).
Authoritative techniques have been heralded as best (Baumrind, Larzelere, \& Owens, 2010), while authoritarian and permissive, among others, have been deemed detrimental to child development (Granic \& Patterson, 2006). African American mothers have been particularly criticized in early literature regarding their authoritarian, or overreactive, parenting behaviors, replete with great demand and little warmth (Iruka, 2009). Although more current literature recognizes the strengths of varying parenting styles in differing environments, research indicates that African American children still have more successful school performance, selfreliance, psychological distress, and delinquency outcomes with parents who are authoritative, that is, firm, accepting, and democratic (Steinberg et al., 1991). Prior research indicates that urban environments elicit more overreactive parenting techniques (McLoyd, 1990), and, given that the majority of African Americans reside in urban locations, context in addition to race may provide the impetus for parenting techniques relevant to external factors. Race is an important variable, however, since there are specific practices unique to in-group members.

Racial socialization is concerned with the messages passed from parent to child about the surrounding environment (Hughes et al., 2006). While various ethnicities have experienced different forms of oppression in the United States, African Americans share a unique history that promotes messages of both resilience and preparation (Stevenson, Davis, \& Abdul-Kabir, 2001). Various demographic and contextual factors explain the ways parents prepare children for the world around them, and parental ethnic identification is a significant predictor for the socialization of African American children (Thomas \& Speight, 1999). Although racial socialization has been used as a moderator of child outcome and parental characteristics, e.g. poverty (Wilson, Foster, Anderson, \& Mance, 2009) and mental health and discipline (Rodriguez, McKay, \& Bannon, Jr., 2008), less is known of the capacity of ethnic identification to impact characteristics of the parent.

Ethnic identification has been described as a factor impacting parenting style in African American families, though studies tend to focus on the relationship of the child's ethnic identity with racial socialization (Sanders Thompson, 1994). Furthermore, studies have looked at demographic characteristics explaining the relationship between 
parenting and child outcome (Fox, Platz, \& Bentley, 1995), yet few investigate ethnic identity as a rationale for parenting techniques and subsequent child effects. Through this exploratory analysis, parental ethnic identification was examined with respect to its ability to mediate the relationship between parenting style and child outcome.

\section{Method}

The current study is a secondary analysis of data from the Early Steps Project which consists of 731 families recruited from the waiting areas of Women, Infants and Children (WIC) Centers in 2002 and 2003. Screening guidelines required a child aged 2133 months old, and who was at-risk for child behavioral problems due to risk factors pertaining to socioeconomic status, family, and the child. This study consists of 171 African American primary caregivers of 5-year-old children. $97.7 \%(N=167)$ of the caregivers were female and ranged in age from $19-72$ years $(M=29.92, S D=7.90)$. The mean educational level of the caregivers was a high school degree. The mean gross family annual income was $\$ 15,000-19,999$, such that $56.4 \%$ of the sample lived below the federal poverty threshold in 2006 (Federal Register, 2006). A research team conducted assessments of caregivers during the annual 3-hour home visit. Caregivers were asked to perform interactive tasks with their 5-year-old, complete additional questionnaires, and were compensated $\$ 100$ for their participation.

Caregivers were asked to complete the Parenting Scale (PS; Arnold, O'Leary, Wolff, \& Acker, 1993) a measure created to assess dysfunctional discipline overreactivity, verbosity, and laxness - within parenting practices; the Multigroup Ethnic Identity Measure (MEIM; Phinney, 1992), 21 items assessing positive ethnic attitudes and belongingness, exploration of ethnic identity, and ethnic practices; and the Child Behavior Checklist (CBCL; Achenbach $\&$ Rescorla, 2001). The CBCL is a 112-item measure assessing child internalizing and externalizing, based on gender and age groups.

\section{Results and Discussion}

Variables were evaluated for normality, and all were within acceptable limits for skewness and kurtosis. Tests of mediation were conducted to see whether ethnic identification mediated the association between parental overreactivity and child externalization and internalization through a Sobel test (as cited in Borders \& Liang, 2011).
The requirements for mediation were not met for either of the dependent variables: overreactivity significantly predicted child externalizing $(p<.001)$ and internalizing $(p<.001)$ behaviors, and overreactivity significantly predicted ethnic identification $(p=.025)$, but ethnic identification did not mediate the relationship between overreactivity and child externalizing or internalizing behaviors ( $p$ 's>.05). (For additional details regarding this analysis please contact the third author.)

This study investigated whether ethnic identification statistically mediated the relationship between parental overreactivity and child behavioral and psychological outcomes. Significant correlations were found between parental overreactivity and child externalizing and internalizing, as well as between parental overreactivity and ethnic identification. Significant mediation was not found, however, indicating that ethnic identification did not explain the relationship between parenting and child behaviors.

In an effort to explore the impact of ethnic identification on parenting style, various other statistical tests should be employed. Ethnic identification and racial socialization have been used in several prior studies as a moderator of the relationship between parenting and child outcomes (Wilson et al., 2009; Rodriguez et al., 2008). Future research could test whether the association between overreactive parenting styles and child outcome varies with parental ethnic identification.

Additionally, ethnic identification may be used as a predictor of child outcome, while parental overreactivity may be used as a mediator. In relation, a regression could determine the percentage of variance in child outcomes explained by parenting style and ethnic identification.

Several limitations may have impacted the findings of this study. The age of the children was 5-years-old, while the norm reference populations for the $\mathrm{CBCL}$ is 6-16 (Achenbach \& Rescorla, 2004). In line with this issue, parents typically utilize racial socialization when the child increases in age (Hughes et al., 2006). Although parental ethnic identification was measured in this study, the impact of racial conversations and personal experiences may impact the psychological and behavioral outcomes of children as they grow in age. Finally, low socioeconomic status may be a limiting factor in the scores of ethnic identification reported by African American caregivers, 


\section{Global Journal of Community Psychology Practice}

considering prior research shows that lower income and less educated African Americans perceive less discrimination and prejudice than their counterparts (Williams, 1999).

The current study reveals a positive significant correlation between parenting overreactivity and ethnic identification. Considering literature notes the benefits of authoritative parenting, even within African American populations, interventions should be mindful of cultural and contextual factors that may steer caregiver behaviors. While praising components of an overreactive parenting style, such as firmness and demandingness, interventions can also address the capacity of caregivers to provide more warmth to their children in order to strive for a more balanced parenting style (Jones et al., 2008). Caregivers with strong ethnic identification can receive specific training to increase their warmth, which tends to lower child aggression (Jones et al., 2008). Interventions with foci on characteristics unique to the African American experience may improve outcomes for parental behaviors and child outcomes.

\section{Summary and Concluding Discussion}

While the positive correlates of a strong, positive ethnic/racial identity are clear in the research, the studies reported here point out the difficulties involved in translating that information into a mechanism for supporting positive youth development. Neither of the interventions demonstrated evidence of any effect on ethnic identity and the parenting study did not find that parental ethnic identity played a mediating role in parenting style or child behavior. There are several possible reasons for this. First, the two communities that received the interventions were both minority/majority communities, ones where the girls had probably received positive messages about their ethnic identity for all of their lives. It seems that the girls entered the interventions with a strong ethnic identity already in place, so there was little for the groups to effect.

Second, as stated in the introduction, there is widespread agreement that the establishment of ethnic identity is a developmental process. Since they grew up in minority majority communities these girls may never have had any reason to question their ethnic identity, but that does not mean they will not do so in the future. This point may be especially important for the Northern New Mexico Hispanic girls, who seemed to have no experience with discrimination based upon ethnicity, and little awareness that the majority culture may hold negative stereotypes regarding Hispanics. It is possible that while the ethnic and cultural themes of the story group were not salient for them as $5^{\text {th }}$ graders, they may become much more important to them as they learn more about the role of Hispanic citizens in American culture. In addition, adolescence has long been considered to be an important time period for identity development. Both groups of girls may find interventions focused on ethnic identity more meaningful during that developmental stage.

The developmental aspect of ethnic identity is equally, if not more important in the parenting study. Many of the studies showing positive effects of authoritarian parenting styles with African American children are conducted with adolescents. It may be that parental ethnic identity can play a mediating role in parenting as adolescents come to consciously interpret their parents' interactions with them in terms of ethnic identity.

It is interesting that in both interventions the gendered aspect of the groups seemed to have a greater effect than the cultural aspects. Since we know that gender is one of the earliest aspects of identity to clearly develop and stabilize, it makes sense developmentally that this aspect might be more salient for latency aged girls than is ethnic or racial identity.

The findings regarding biculturality and bicultural competence are also interesting. There is little research on the specific effects of growing up in a well established minority majority community in the United States. The suggestions from this study that those communities may be supporting the development of a bicultural identity and bicultural competence in their children are worthy of further investigation.

Finally, it is important to note that while the two interventions reported in this paper did not demonstrate an effect on ethnic identity, there is a great deal of evidence in the literature that culturally anchored interventions demonstrated increased effectiveness. At the very least there are ethical and pragmatic reasons for insuring that interventions match with the cultural values of the communities in which they are presented.

\section{References}




\section{Global Journal of Community Psychology Practice}

Achenbach, T.M. (1991). Manual for the youth self-report and 1991 profile. Burlington: University of Vermont, Department of Psychiatry.

Achenbach, T. M. \& Rescorla, L. A. (2004). The Achenbach System of Empirically Based Assessment (ASEBA) for Ages 1.5 to 18 Years. In M.E.Maruish (Ed.), The use of psychological testing for treatment planning and outcomes assessment: Volume 2: Instruments for children and adolescents (3rd ed) (pp. 179-213). Mahwah, NJ, US: Lawrence Erlbaum Associates Publishers.

Atencio, P. (1991). Cuentos From My Childhood: Legends and Folktales of Northern New Mexico. Santa Fe: Museum of New Mexico Press.

Arbona, C., Jackson, R.H., McCoy, A., \& Blakely, C. (1999). Ethnic identity as a predictor of attitudes of adolescents toward fighting. Journal of Early Adolescence, 19, 323-340.

Arnold, D. S., O'Leary, S. G., Wolff, L. S., \& Acker, M. M. (1993). The Parenting Scale: A measure of dysfunctional parenting in discipline situations. Psychological Assessment, 5, 137-144.

Baumrind, D., Larzelere, R. E., \& Owens, E. B. (2010). Effects of preschool parents' power assertive patterns and practices on adolescent development. Parenting: Science and Practice, 10, 157-201.

Belgrave, F.Z., Chase-Vaughn,G., Gray, F. Addision, J.D., \& Cherry, V.R. (2002). The effectiveness of a culture-and genderspecific intervention for increasing resiliency among African American preadolescent females. Journal of Black Psychology, 26, 133-147.

Borders, A. L. \& Liang, C. T. (2011). Rumination partially mediates the associations between perceived ethnic discrimination, emotional distress, and aggression. Cultural Diversity and Ethnic Minority Psychology, 17, 125-133.

Bracken, B. A. (1992). Examiner's Manual for the Multidimensional Self Concept Scale. Austin, TX: Pro-Ed.
Caldwell, C.H., Zimmerman, M.A., Bernat, D.H., Sellers, R.M. \& Notaro, P.C. (2002). racial identity, maternal support, and psychological distress among African American adolescents. Child Development, 73, 1322-1336.

Caldwell, C. H., Kohn-Wood, L., SchmeelkCone, K., Chavous, T., \& Zimmerman, M. (2004). Racial discrimination and racial identity as risk or protective factors for violent behaviors in African American young adults. American Journal of Community Psychology, 33, 91-106.

Chicago Public Schools Annual Report, 2003.

Dubois, D.L., Braxton, C.B., Swenson, L.P., Tevendale, H.D., \& Hardesty, J.L. (2002). Race and gender influence on adjustment in early adolescence: Investigation of an integrative model. Journal of Early Adolescence, 20, 12-43.

Fordham, S., \& Ogbu, J. U. (1986). Black students' school success: Coping with the "burden of acting White." The Urban Review, 18, 176-206.

Fox, R. A., Platz, D. L., \& Bentley, K. S. (1995). Maternal factors related to parenting practices, developmental expectations, and perceptions of child behavior problems. The Journal of Genetic Psychology: Research and Theory on Human Development, 156, 431-441.

Granic, I. \& Patterson, G. R. (2006). Toward a comprehensive model of antisocial development: A dynamic systems approach. Psychological Review, 113, 101-131.

Hughes, D., Rodriguez, J., Smith, E. P., Johnson, D. J., Stevenson, H. C., \& Spicer, P. (2006). Parents' ethnic-racial socialization practices: A review of research and directions for future study. Developmental Psychology, 42, 747-770.

Iruka, I. U. (2009). Ethnic variation in the association between family structures and practices on child outcomes at 36 months: Results from Early Head Start. Early Education and Development, 20, 148-173.

Irving, M.A. \& Hudley, C. (2008). Oppositional Identity and Academic Achievement Among 


\section{Global Journal of Community Psychology Practice}

African American Males. In J. Ogbu (Ed.), Minority Status, Oppositional Culture, and Schooling, pp. 374-394. New York:

Routledge.

Jones, D. J., Forehand, R., Rakow, A., Colletti, C. J. M., McKee, L., \& Zalot, A. (2008). The specificity of maternal parenting behavior and child adjustment difficulties: A study of inner-city African American families. Journal of Family Psychology, 22, 181-192.

Marcia, J. E. (1996). Development and validation of ego identity status. Journal of Personality and Social Psychology, 3, 551558.

McCreary, M.L., Slavin, L.A., \& Berry, E.J. (1996). Predicting problem behavior and self-esteem among African American adolescents. Journal of Adolescent Research, 11, 216-234.

McMahon, S. \& Watts, R. (2002). Ethnic identity in urban African American youth: Exploring links with self-worth, aggression and other psychosocial variables. Journal of Community Psychology, 30, 411-432.

McLoyd, V. C. (1990). The impact of economic hardship on Black families and children: Psychological distress, parenting, and socioemotional development. Child Development, 61, 311-346.

Nobles, W.W. \& Goddard, L.L. (1992). An African-centered model of prevention for African American youth at high risk. In $A n$ African-centered model of prevention for African American youth at high risk (DHHS publication no. ADM 921925, pp.87-92). U.S. Department of Health and Human Services.

Phinney, J. S. \& Kohatsu, E. L. (1997). Ethnic and racial identity development and mental health. In J. Schulenberg, J. L. Maggs, \& K. Hurrelmann (Eds.), Health risks and developmental transitions during adolescence (pp. 420 -443). New York: Cambridge University Press.

Resnicow, K., Baranowski, T., Ahluwahlia, J., \& Braithwaite, R. (1999). Cultural sensitivity in pubic health: Defined and demystified. Ethnicity and Disease, 9, 1021.

Rodriguez, J., McKay, M. M., \& Bannon, W. M., Jr. (2008). The role of racial socialization in relation to parenting practices and youth behavior: An exploratory analysis. Social Work in Mental Health, 6, 30-54.

Romero, A. \& Roberts, R. (1998). Perception of discrimination and ethno-cultural variables in a diverse group of adolescents. Journal of Adolescence, 21, 641-656.

Sanders Thompson, V. L. (1994). Socialization to race and its relationship to racial identification among African Americans. Journal of Black Psychology, 20, 175-188.

Sellers, R. M., Caldwell, C. H. Schmeelk-Cone, K. H., \& Zimmeman, M. A. (2003). Racial identity, racial discrimination, perceived stress, and psychological distress among African American young adults. Journal of Health and Social Behavior, 44, 302-317.

Sellers, R.M. \& Shelton, J. N. (2003). The role of racial identity in perceived racial discrimination. Journal of Personality and Social Psychology, 84, 1079-1092.

Smith, E.P. \& Brookins. (1997). Toward the development of an ethnic identity measure for African American youth. Journal of Black Psychology, 23, 358-377.

Steinberg, L., Mounts, N. S., Lamborn, S. D., \& Dornbusch, S. M. (1991). Authoritative parenting and adolescent adjustment across varied ecological niches. Journal of Research on Adolescence, 1, 19-36.

Stevenson, H. C., Davis, G., \& Abdul-Kabir, S. (2001). Stickin' to, watchin' over, and gettin' with: An African American parent's guide to discipline. San Francisco, CA: Jossey-Bass.

Thomas, A. J. \& Speight, S. L. (1999). Racial identity and racial socialization attitudes of African American parents. Journal of Black Psychology, 25, 152-170.

Williams, D. R. (1999). Race, socioeconomic status, and health: The added effects of racism and discrimination. In N.E.Adler, M. 


\section{Global Journal of Community Psychology Practice}

Marmot, B. S. McEwen, \& J. Stewart (Eds.), Socioeconomic status and health in industrial nations: Social, psychological, and biological pathways (pp. 173-188). New York, NY, US: New York Academy of Sciences.

Williams, D. R. \& Williams-Morris, R. (2000). Racism and mental health: The African-
American experience. Ethnicity and Health, 5, 243-268.

Wilson, D., Foster, J., Anderson, S., \& Mance, G. (2009). Racial socialization's moderating effect between poverty stress and psychological symptoms for African American youth. Journal of Black Psychology, 35, 102-124. 